\title{
The Influence of Material Selection and Pre-Deformation on the Performance of Foil Bearing
}

\author{
Hao LI***, Haipeng GENG***, Hao LIN*, Sheng FENG* \\ *State Key Laboratory for Strength and Vibration of Mechanical Structures, Xi'an Jiaotong University, Xi'an, China \\ **School of Mechanical Engineering, Xi'an Jiaotong University, Xi'an, China \\ Corresponding author. E-mail: genghaipeng@mail.xjtu.edu.cn
}

cross'ref http://dx.doi.org/10.5755/j01.mech.26.3.26764

\section{Introduction}

As flexible bearings with excellent stability at high speed and high temperature, complaint foil bearings (CFBs) have been widely used in high-speed rotating machinery [1], especially light-loading situation. The CFB is mainly composed of top foil, bump foil, and bearing sleeve [2]. Top foil and journal consist a friction pair to shape a hydrodynamic wedge to achieve the supporting effect $[3,4]$. The research on CFBs mainly focuses on its structural form, including elastic structure and surface geometry [5]. There are relatively few studies on the selection of foil materials. Researchers generally believed that the preferred material for foil bearings is nickel-based alloy for their higher strength and oxidation resistance, such as Inconel X-750 [6], while the stainless steel like SUS321 is usually used in the normal temperature and light-load system.

In fact, the static strength and lifetime are still the main concerns in the selection of foil material, but there is little literature on the discussion about the dynamic performance. However, with the continuous improvement of speed and power, the vibration problem of CFBs is becoming more and more obvious. In the rotor system supported by CFBs, the damping phenomenon mainly consists of dynamic pressure damping of lubricating film, Coulomb friction. Therefore, the role of material damping in vibration absorption and isolation of the rotor system is more essential.

Material damping refers to the phenomenon of energy consumption caused by the interaction between internal grains in the process of vibration. This phenomenon was first discovered by British scientists in $\mathrm{Mn}-\mathrm{Cu}$ alloy, and then researchers found similar appearance in $\mathrm{Mn}-\mathrm{Ni}$, Ti-Ni and other alloys.

In this paper, the damping coefficient and elastic modulus of Inconel X-750 and SUS321 are studied considering the temperature and pre-deformation. Then the results are put into the calculation of CFBs, and the influence of the pre-deformation on rotor systems is discussed. Finally, the result indicates that for the foil bearing supporting the rotor system shown in this paper, the Inconel X-750 with 10\% pre-deformation is the best choice.

\section{Material test}

The experimental materials used in this paper are the stainless steel SUS321 and the nickel-based alloy Inconel X-750. Their components are shown in Tables 1 and 2 , respectively.

For the Inconel $\mathrm{X}-750$, heat treatment has a great influence on their mechanical properties. Different processes affect the grain size and the distribution of precipitated strengthening phases. At present, the heat treatment process of Inconel X-750 aim at bars, forgings and rings, which meet the standards of AMS 5668, AMS 5698 and AMS 5699, respectively [7]. For this reason, a set of heat treatment process for Inconel X-750 foil material has been summarized in our experiments, as shown in Table 3 . The mechanical properties of the foil strip treated by this process are better than those in the literature [8] (break strength $1199 \mathrm{MPa}$, elongation $16.1 \%$ ). The equipment used for heat treatment is WZC-30 vacuum gas quenching furnace with the highest working temperature of $1350^{\circ} \mathrm{C}$, and the vacuum degree can reach $8 \times 10^{-3} \mathrm{~Pa}$ in heating chamber (Fig. 1).

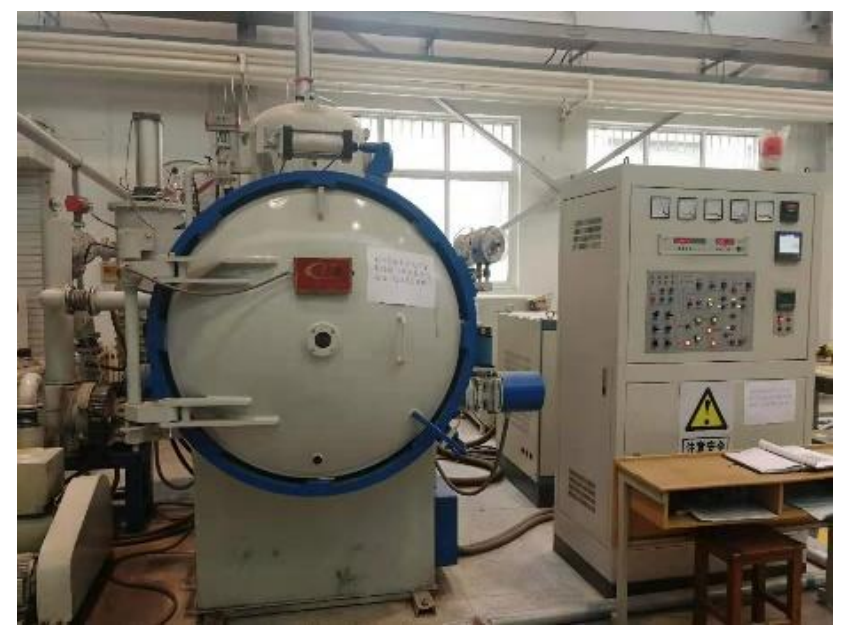

Fig. 1 WZC-30 vacuum gas quenching furnace

The nickel-based alloy foil and stainless steel foil are made into damping test sheets with a size of $35 \mathrm{~mm} \times 4 \mathrm{~mm} \times 0.11 \mathrm{~mm}$. The surface is polished and put into alcohol to remove the oxide layer. They are dried by a blower for spare after cleaning in ultrasonic cleaning machine.

Using DMA 242E shown in Fig. 2 to test the temperature-damp performance of the foil with single cantilever temperature scanning mode, the preload is $10 \mathrm{~N}$, the excitation frequency is $333 \mathrm{~Hz}$, the amplitude of vibration is $100 \mu \mathrm{m}$, and the temperature range is $50-280^{\circ} \mathrm{C}$, which are similar to the operating condition of CFBs. The furnace is heated by electric heating wire, and the heating rate is $5^{\circ} \mathrm{C} / \mathrm{min}$. The elastic modulus of material is measured at the same time.

In order to study the effect of pre-deformation on the damping properties of Inconel X-750, the tensile specimens as shown in Fig. 3 is prepared. AG-X10KN vertical 
electronic universal testing machine is used for pre-stretching. The stretching rate is $0.2 \mathrm{~mm} / \mathrm{min}$, and the deformation is $0 \%, 5 \%, 10 \%$, respectively. After stretching, the same size of damping testing sample is intercepted on the specimen.

The components of Inconel X-750

Table 1

\begin{tabular}{|c|c|c|c|c|c|c|c|c|}
\hline & $\mathrm{Ni}$ & $\mathrm{Cr}$ & $\mathrm{Fe}$ & Co & $\mathrm{Nb}+\mathrm{Ta}$ & $\mathrm{Ti}$ & $\mathrm{Al}$ & $\mathrm{C}$ \\
\hline Min & 70.0 & 14.0 & 5.0 & & 0.70 & 2.25 & 0.40 & 0.02 \\
\hline Max & & 17.0 & 9.0 & 0.25 & 1.2 & 2.75 & 1.0 & 0.06 \\
\hline & $\mathrm{S}$ & $\mathrm{P}$ & $\mathrm{Zr}$ & B & $\mathrm{Si}$ & $\mathrm{Cu}$ & $\mathrm{Mn}$ & $\mathrm{V}$ \\
\hline $\begin{array}{l}\text { Min } \\
\text { Max }\end{array}$ & 0.01 & 0.008 & 0.05 & 0.007 & 0.50 & 0.50 & 1.00 & 0.1 \\
\hline
\end{tabular}

Table 2

The components of SUS321

\begin{tabular}{|c|c|c|c|c|c|c|c|c|}
\hline & $\mathrm{Ni}$ & $\mathrm{Cr}$ & $\mathrm{Fe}$ & $\mathrm{Si}$ & $\mathrm{Mn}$ & $\mathrm{S}$ & $\mathrm{Ti}$ & $\mathrm{C}$ \\
\hline Min & 8.0 & 17.0 & Remain & 0 & 0 & 0 & $5 \times(\mathrm{C}-0.02)$ & 0 \\
Max & 11.0 & 19.0 & & 1 & 2 & 0.03 & 0.8 & 0.12 \\
\hline
\end{tabular}

Table 3

Heat treatment process for Inconel X-750

\begin{tabular}{|c|c|c|c|c|}
\hline & Treatment & Temperature & Time & Cooling \\
\hline Step 1 & Annealing & $1050^{\circ} \mathrm{C}$ & $2 \mathrm{hr}$ & Air cooling \\
Step 2 & Solid solution & $840^{\circ} \mathrm{C}$ & $4 \mathrm{hr}$ & Air cooling \\
Step 3 & Aging & $750^{\circ} \mathrm{C}$ & $10 \mathrm{hr}$ & Furnace cooling to 620 ${ }^{\circ} \mathrm{C}$ \\
& & $620^{\circ} \mathrm{C}$ & $12 \mathrm{hr}$ & Air cooling \\
\hline
\end{tabular}

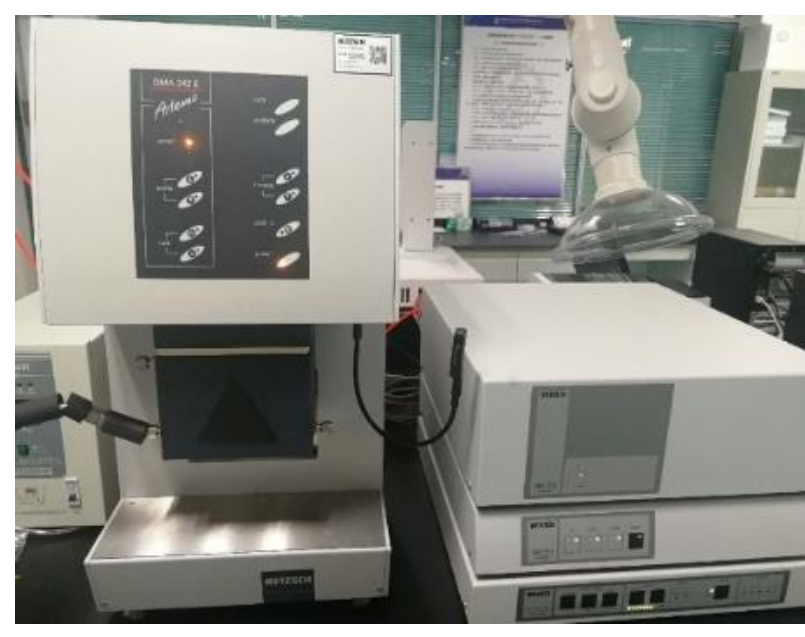

Fig. 2 Dynamic analysis system (DMA 242E)

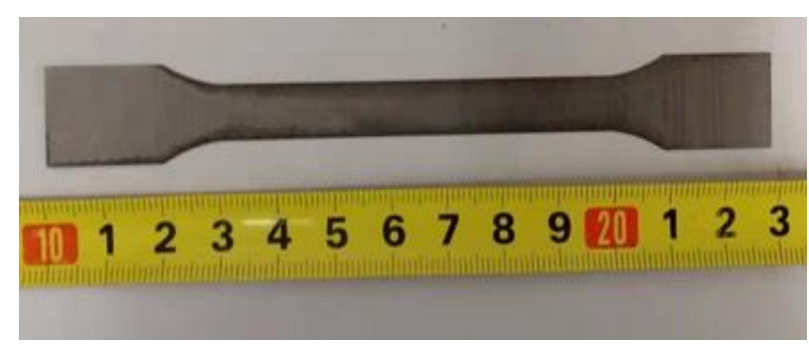

Fig. 3 Inconel X-750 tensile specimen

Fig. 4 shows the variation of damping coefficient $\eta$ and elastic modulus $E$ of SUS321 and Inconel X-750 with different temperature. It can be seen that the elastic modulus of Inconel X-750 is larger than SUS321, and both of them decrease with the increase of temperature. Because the temperature increment enlarges the atomic distance and weaken the binding force. It can be clearly noticed that the elastic modulus $E$ and the damping coefficient $\eta$ of Inconel X-750 both decline with the enhanced temperature. The elastic modulus $E$ of SUS321 used in the experiment fluctuates

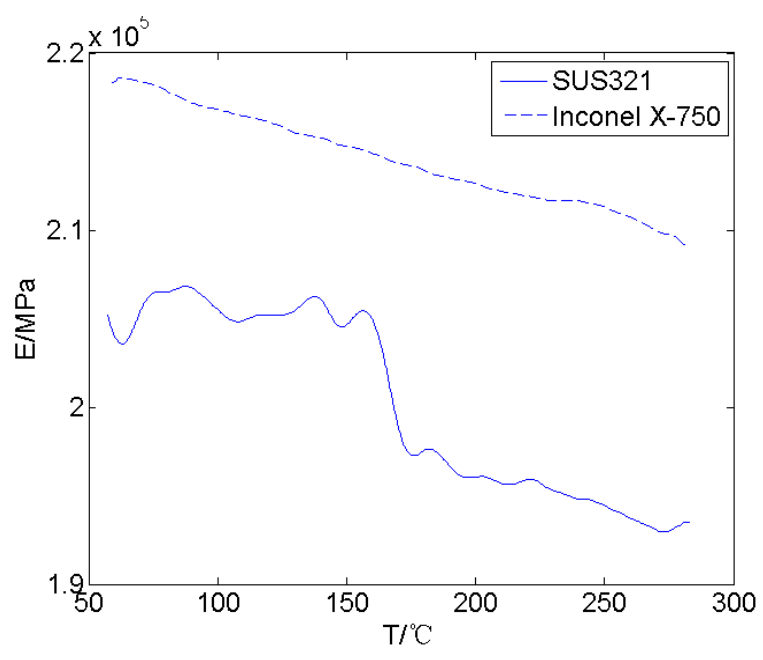

a) The elastic modulus $E$

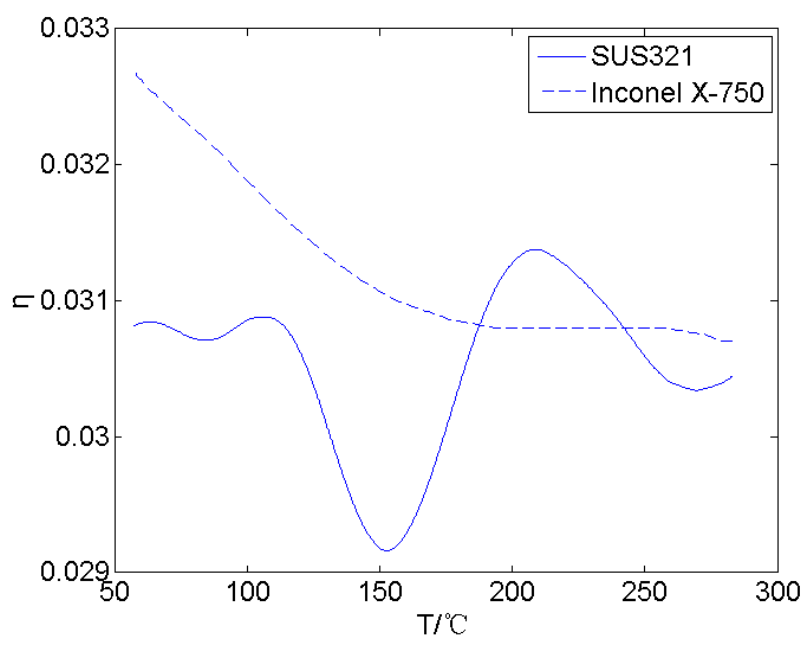

b) The damping coefficient $\eta$

Fig. 4 Variation of damping coefficient $\eta$ and elastic modulus $E$ of SUS321 and Inconel X-750 
sharply near $170^{\circ} \mathrm{C}$, and the same situation also happens on the damping coefficient $\eta$, except the temperature is advanced by $15^{\circ} \mathrm{C}$. Considering the elastic modulus $E$ is not sensitive to the organization, it is speculated that this phenomenon may be due to defects in the foil during machining. Both two kinds of strips are machined by the same method, i.e. wire-electrode cutting and roll-bending, which also shows that SUS321 foil is easier to produce faultiness than Inconel X-750 foil during processing. When CFBs operate, the temperature of foils increase rapidly in a short time due to dry friction during start-stop stage and occasional rubbing at high speed. Although they are covered with thermal barrier coating, the base metal is facing the test of high temperature. Therefore, form this point of view, using Inconel X750 to manufacture the foil bearing is better than SUS321.

Fig. 5 shows the variation of damping coefficient and elastic modulus of Inconel X-750 with different pre-deformation. It can be seen that the pre-deformation can reduce the elastic modulus, which is mainly due to the residual stress in the foil. At the same time, the pre-deformation improves the damping coefficient of the strip. When the deformation is $10 \%$, the damping coefficient raises slowly with the increase of temperature. However, when the pre-deformation is $10 \%$, the elastic modulus falls rapidly at $170^{\circ} \mathrm{C}$, which may due to internal defects of alloy caused by excessive plastic deformation.

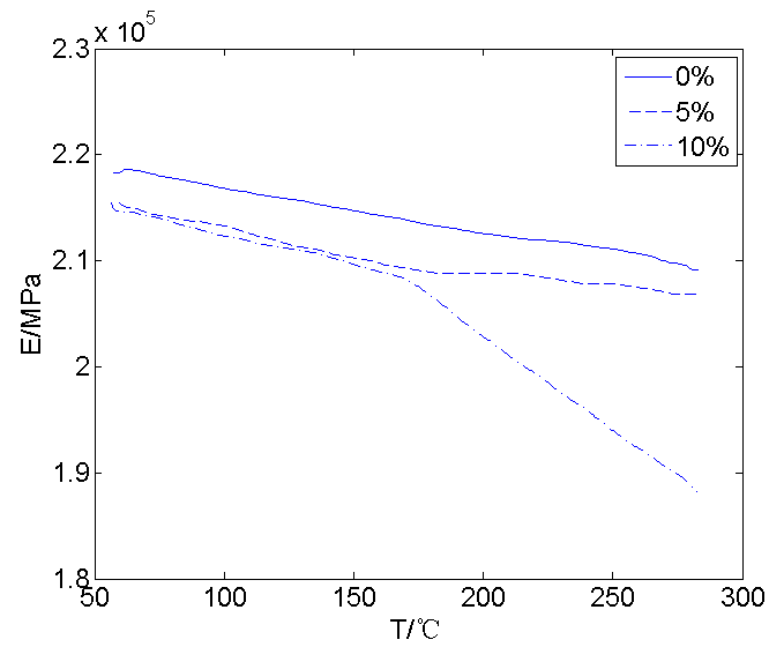

a) Elastic modulus $E$

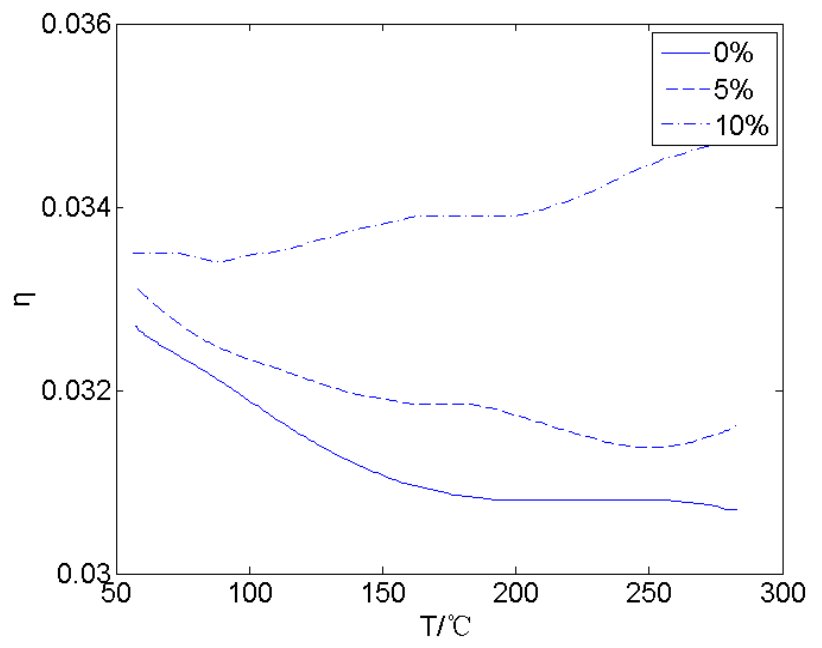

b) Damping coefficient $\eta$

Fig. 5 Variation of damping coefficient $\eta$ and elastic modulus $E$ with different pre-deformation
In the working process of foil bearing, the gas pressure leads to the elastic deformation of the foil to achieve flexibility, which requires the yield strength of foil to be as high as possible to ensure the service life of the bearing. The yield strength of Inconel X-750 foil with different pre-deformation is shown in the Fig. 6. The yield strength rises with the pre-deformation. This is because deformation rises the dislocation density inside the metal and enhance the deformation resistance. This phenomenon also illustrates that pre-deformation of foil before operation can enhance the allowable load of bearing.

In order to further study, the mechanism of the predeformation effect on the damping coefficient, the energy spectrum analysis of Inconel X-750 foil is carried out as shown in Fig. 7. It can be seen that the zonal Mn-rich zone is formed, and its Mn content is obviously higher than the average level of the base material shown in Table 1. According to the solid metal theory, martensite is the main damping source of alloy [9], so the incresement of martensite can significantly improve the damping coefficient. The formation of Mn-rich zone affects the martensite transformation temperature and raises the number of thermo-elastic martensite. Pre-deformation can cause stress-induced martensite formation. At the same time, plastic deformation increases the density of dislocations, and the reciprocating movement of dislocations intensifies the internal friction, which results in the enhancement of damping coefficient.

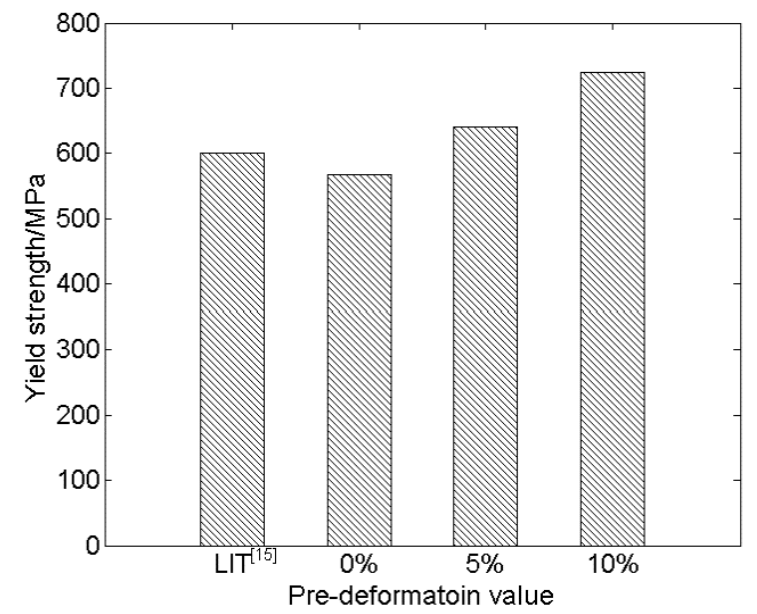

Fig. 6 Yield strength of Inconel X-750 with different predeformation

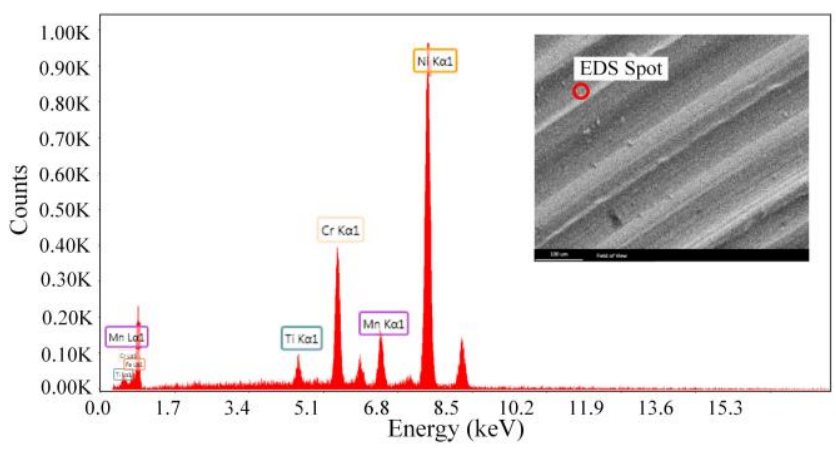

Fig. 7 Energy spectrum analysis of Inconel X-750 foil with $10 \%$ pre-deformation

\section{CFB system analysis}

From the above analysis, it can be seen that the appropriate pre-deformation of Inconel X-750 foil can enhan- 
ce the damping coefficient, which is obviously benefitcial to suppress the vibration of rotor system. In this section, we discuss the effect of damping enhancement caused by foil pre-deformation on the vibration characteristic of the rotor system.

When the CFB serves in non-extreme conditions, its hydrodynamic lubrication behavior can be described by Reynold equation as follow [10]:

$$
\nabla\left(\frac{p h^{3}}{12 \mu} \nabla p\right)=\nabla(p h)\{U\}+\frac{\partial}{\partial t}(p h), ;
$$

where: $p$ is film pressure; $h$ is film thickness; $\mu$ is gas viscosity; $U$ is relative linear velocity of journal and bearing; $t$ is time.

Fig. 8 is the model of foil bearing, and the film thickness can be expressed as Eq. (2) [11,12]:

$$
\begin{aligned}
& h=e+C \cos (\varphi+\psi)+W_{t} \\
& W_{t}=\frac{C_{B}}{C_{B}+K_{B} \Delta t} W_{t-\Delta t}+\frac{\Delta t}{C_{B}+K_{B} \Delta t}\left(p-p_{a}\right), \\
& C_{B}=\frac{\eta}{v} K_{B}
\end{aligned}
$$

where: $e$ is eccentricity between journal and bearing; $C$ is nominal clearance; $\varphi$ is circumferential position of bearing; $\psi$ is offset angle of journal; $W_{t}$ is foil deformation at $t ; C_{B}$ is foil damping; $K_{B}$ is foil stiffness; $p a$ is environment pressure; $v$ is disturbance ratio.

In the actual process, there are many factors that may disturb rotor system, such as mass imbalance, rotor rubbing, unbalanced magnetic pull force and so on. Therefore, the vibration of rotor system in practical circumstance is inevitable. In this paper, only the unbalanced mass of the rotor is considered, and the exciting force can be described without considering the initial phase as Eq. (3):

$$
\left[\begin{array}{c}
F_{x m} \\
F_{y m}
\end{array}\right]=m_{u} \omega^{2} r\left[\begin{array}{c}
\cos (\omega t) \\
\sin (\omega t)
\end{array}\right]
$$

where: $F_{x}$ and $F_{y}$ are the exciting force caused by mass imbalance in $x$ and $y$ direction; $m_{u}$ is unbalanced mass; $\omega$ is the angular velocity of journal; $r$ is journal radius.

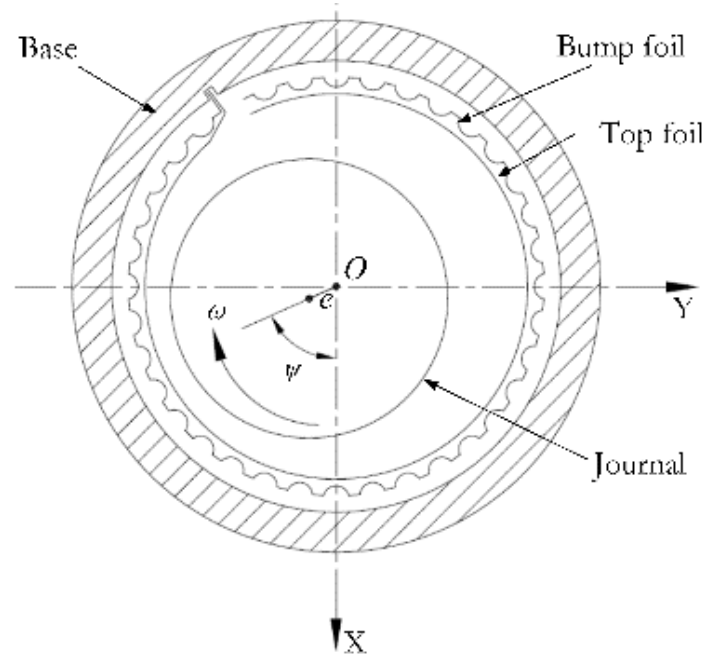

Fig. 8 Model of foil bearing and verification of calculation results

The parameters of the rotor system used for the analysis in this section are shown in Table 4.

Table 4

The parameters of rotor system

\begin{tabular}{|c|c|}
\hline Parameters & Value \\
\hline Mass of rotor, $\mathrm{kg}$ & 2 \\
Diameter of rotor, mm & 25 \\
Rotational speed, rpm & 20000 \\
Number of bearings & 2 \\
Nominal clearance, mm & 0.015 \\
Width of bearing, mm & 25 \\
Acting angle of bearing, & 360 \\
Gas viscosity, Pa.s & $17.9 \times 10-6$ \\
Disturbance ratio & 1 \\
Environmental pressure, MPa & 0.1013 \\
\hline
\end{tabular}

The unbalanced mass is classified as G1.0 according to the international industrial standard (ISO 19401:2003), i.e. $m_{u}=39.7 \mathrm{mg}$.

The CFB provides the bearing capacity, stiffness and damping coefficient of the supporting system, while the unbalanced mass of the rotor means exciting load. Therefore, the mass unbalanced model can be connected with the hydrodynamic lubrication model through the vibration of the rotor system as Eq. (4), then the interaction between the two models can be analysed.

$$
m\left[\begin{array}{l}
\ddot{x} \\
\ddot{y}
\end{array}\right]+\left[\begin{array}{ll}
c_{x x} & c_{x y} \\
c_{y x} & c_{y y}
\end{array}\right]\left[\begin{array}{l}
\dot{x} \\
\dot{y}
\end{array}\right]+\left[\begin{array}{cc}
k_{x x} & k_{x y} \\
k_{y x} & k_{y y}
\end{array}\right]\left[\begin{array}{l}
x \\
y
\end{array}\right]=\left[\begin{array}{c}
F_{x g} \\
F_{y g}
\end{array}\right]+\left[\begin{array}{c}
F_{x m} \\
F_{y m}
\end{array}\right],
$$

where: $m$ is rotor mass; $\left[k_{i j}\right]$ and $\left[c_{i j}\right]$ are the stiffness and damping matrix of rotor system; $F_{x g}$ and $F_{y g}$ are aerodynamic force in $x$ and $y$ direction, respectively.

Fig. 9 shows the rotor trajectory with different predeformed foil, in which the horizontal and vertical coordinates represent the dimensionless positions in $\mathrm{X}$ and $\mathrm{Y}$ direction respectively $([X, Y]=[x, y] / C)$. The minimum envelope circle of vibration trajectory is found by genetic algorithm, and the radius is used to characterize the intensity of vibration. As can be seen, the vibration radius of (c) is reduced by about $5 \%$ compared with (a), which means about $0.08 \mu \mathrm{m}$ vibration is suppressed. Although the declination seems small, its advantage is obviously considerable, for the nominal clearance is only $15 \mu \mathrm{m}$ and the vibration radius must be restricted with in $1 \mu \mathrm{m}$ generally. And with the enhancement of pre-deformation, the vibrating center moves away from the origin, which intensify the risk of rubbing. It is mainly due to the reduction of elastic modulus, which decrease the stiffness of foil. At the same time, considering that pre-deformation can thin the foil, and large pre-stress goes ill with long-life operation of CFB, the pre-deformation degree in manufacturing process still needs further research. 


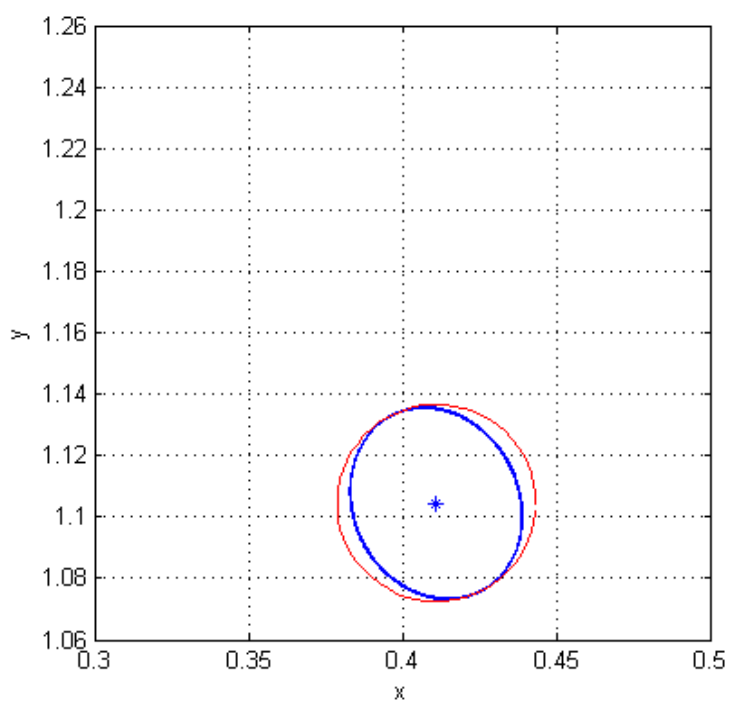

a) $0 \%$ pre-deformation

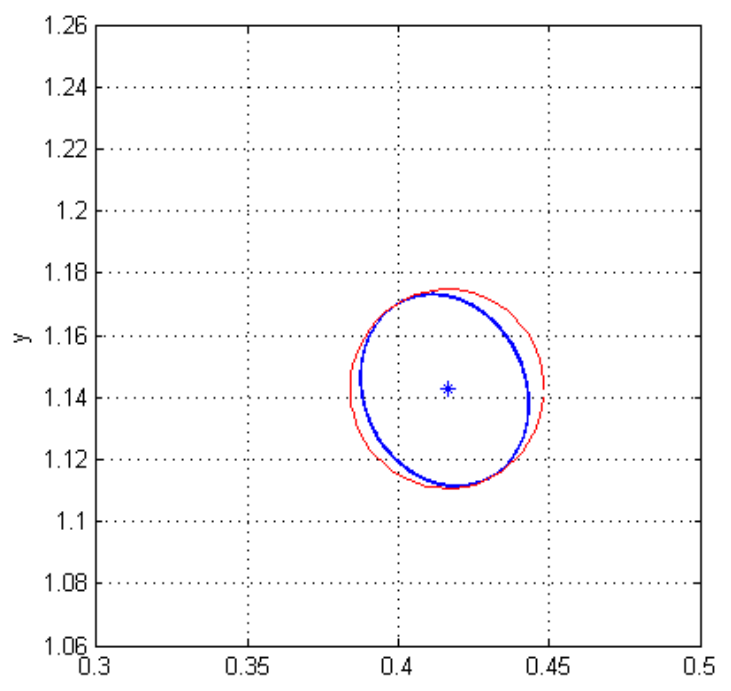

b) $5 \%$ pre-deformation

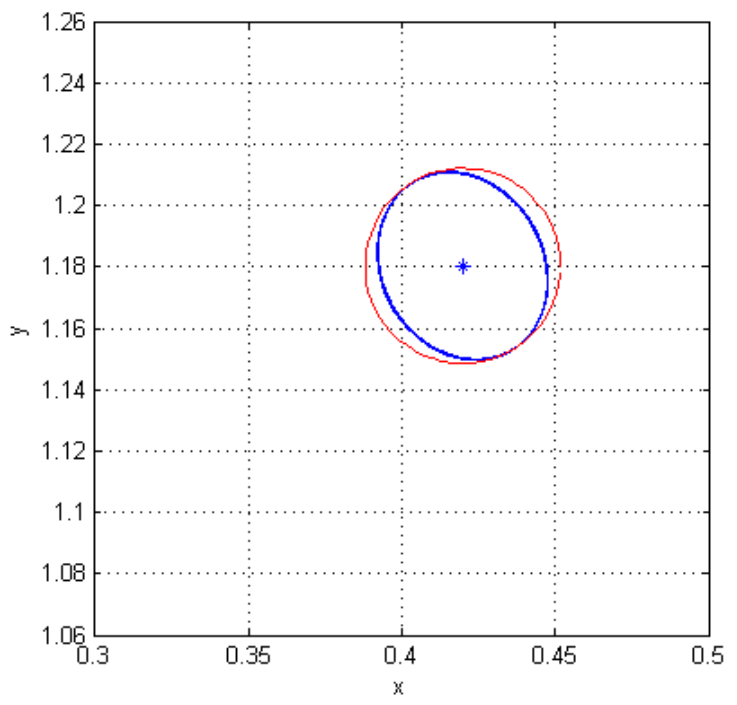

c) $10 \%$ pre-deformation

Fig. 9 Trajectory of rotor with different pre-deformed foil

\section{Conclusion}

An experimental work is carried out to study the effect of operating temperature on the damping coefficients and the elastic modulus of Inconel X-750 and SUS321, which indicates the Inconel X-750 is more suitable for manufacture the foil bearing. Then, the influence of pre-deformation on the damping coefficients and the elastic modulus of Inconel X-750 are discussed. The elastic modulus falls with the increase of pre-deformation, which is mainly due to the deformation weaken the bonding force between atomic. At the same time, the damping coefficient enhances with the raise of pre-deformation, which may be caused by thermo-elastic martensite induced by Mn-rich zone in foil and stress-induced martensite produced by pre-deformation. And pre-deformation can enhance the yield strength of strips to serve heavy-loading machine better. For the bearing parameters used in this paper, when the pre-deformation is $10 \%$, the vibration radius of rotor is reduced by $5 \%$, which shows that pre-deformation is beneficial to the vibration reduction of foil bearing-rotor system. The decrease of elastic modulus caused by pre-deformation reduces the stiffness of foil bearing, which intensify the rubbing risk. Therefore, for the foil bearing supporting the rotor system shown in this paper, the Inconel X-750 with $10 \%$ pre-deformation is the best choice.

\section{References}

1. Dellacorte, C; Valco, M. 2000. Load Capacity Estimation of Foil Air Journal Bearings for Oil-Free Turbomachinery Applications, ASLE Transactions 43(4):795-801.

http://dx.doi.org/10.1080/10402000008982410.

2. Mohsen, S; Heshmat, H. 2000. On the fluid flow and thermal analysis of a compliant surface foil bearing and seal, ASLE Transactions 43(2):318-324.

http://dx.doi.org/10.1080/10402000008982346.

3. Heshmat, H; Hryniewicz, P. 2005. Low-friction wearresistant coatings for high-temperature foil bearings, Tribology International 38(11):1059-1075. http://dx.doi.org/10.1016/j.triboint.2005.07.036.

4. Heshmat, H. 1983. Analysis of Gas-Lubricated Foil Journal Bearings, Asme J. lubr. technol 105(4):647-652. http://dx.doi.org/10.1115/1.2831272.

5. Feng, K; Wang, F.Y. 2016. Influence of radial clearance and processing technology on structural properties of gas foil bearing, Journal of Aerospace Power 31(11):2773-2780.

http://dx.doi.org/10.13224/j.cnki.jasp.2016.11.028.

6. Brian, D; DellaCorte, C. 2009. Design, Fabrication, and Performance of Foil Gas Thrust Bearings for Microturbomachinery Applications 131(1):012301. http://dx.doi.org/10.1115/1.2966418.

7. Dellacorte, C; Radil, K. 2008. Design, fabrication, and performance of open source generation I and II compliant hydrodynamic gas foil bearings, Tribology Transactions 51(3):254-264. http://dx.doi.org/10.1080/10402000701772579.

8. Duan, W. B. 2011. Numerical and experimental investigation of bump foil forming process for foil air bearings, Advanced research on industry, information systems and material engineering 1:1-7. http://dx.doi.org/10.4028/AMR_204-210.2103.

9. Kim, S; Seidl, M. 2011. Theory of Metal-Solid Electrolyte Interface, MRS Online Proceeding Library Archive 1:135-141. http://dx.doi.org/10.1557/proc-135-95. 
10. Larsen, J. 2015. Experimental and theoretical analysis of a rigid rotor supported by air foil bearings, Mécanique \& Industries 1:12-25.

http://dx.doi.org/10.1051/meca/2014066.

11. Kim, D. 2007. Parametric studies on static and dynamic performance of air foil bearings with different top foil geometries and bump stiffness distributions, Journal of Tribology 129 (2):354-364. http://dx.doi.org/10.1177/1350650115621015.

12. Bhore, S; Darpe, A. 2013 Nonlinear dynamics of flexible rotor supported on the gas foil journal bearings, Journal of Sound and Vibration 332(20):5135-5150. http://dx.doi.org/10.1016/j.jsv.2013.04.023.
Hao Li, Haipeng Geng, Hao Lin, Sheng Feng

THE INFLUENCE OF MATERIAL SELECTION AND PRE-DEFORMATION ON THE PERFORMANCE OF FOIL BEARING

S u m m a r y

Material selection is one of the most important steps in the manufacturing process of foil bearing. In this study, an experimental work is carried out to study the effect of operating temperature on the damping coefficients and the elastic modulus of Inconel X-750 and SUS321. Then, the influence of pre-deformation on the damping coefficients and the elastic modulus of Inconel X-750 are discussed. Finally, this paper calculates the rotor trajectory supported by the foil bearing considering the different predeformation of the foil. The results show that for the foil bearing supporting the rotor system shown in this paper, the Inconel X-750 with $10 \%$ pre-deformation is the best choice.

Keywords: foil bearing, damping coefficient, elastic modulus, rotor trajectory, Inconel X-750.

Received September 09, 2019 Accepted June 02, 2020 